\title{
Stratification of risk to the surgical team in removal of small arms ammunition implanted in the craniofacial region: case report
}

\author{
Jonathan A. Forbes, MD, ${ }^{1}$ lan Laughlin, BS, ${ }^{2}$ Shane Newberry, MD, ${ }^{3}$ Michael Ryhn, DDS, ${ }^{4}$ \\ Jason Pasley, DO, ${ }^{5}$ and Travis Newberry, MD ${ }^{6}$
}

${ }^{1}$ Department of Neurological Surgery, David Grant Medical Center, Travis AFB, Davis, California; ${ }^{2}$ United States 47th OD CO (EOD), Fort Hood, Killeen, Texas; ${ }^{3}$ Department of Radiology, San Antonio Military Medical Center, Lackland AFB, San Antonio, Texas; ${ }^{4}$ Department of Oral Maxillofacial Surgery, Tripler Medical Center, Honolulu, Hawaii; ${ }^{5}$ Department of Surgery, University of Maryland, CSTARS-Baltimore RA Cowley Shock Trauma, Baltimore, Maryland; and ${ }^{6}$ Department of Otolaryngology, San Antonio Military Medical Center, Fort Sam Houston, San Antonio, Texas

\begin{abstract}
In cases of penetrating injury with implantation of small arms ammunition, it can often be difficult to tell the difference between simple ballistics and ballistics associated with unexploded ordnances (UXOs). In the operative environment, where highly flammable substances are often close to the surgical site, detonation of UXOs could have catastrophic consequences for both the patient and surgical team. There is a paucity of information in the literature regarding how to evaluate whether an implanted munition contains explosive material. This report describes a patient who presented during Operation Enduring Freedom with an implanted munition suspicious for a UXO and the subsequent workup organized by Explosive Ordnance Disposal (EOD) Company prior to surgical removal. Clinical risk factors for UXOs include assassination attempts and/or wartime settings. Specific radiological features suggestive of a UXO include projectile size greater than 7.62-mm caliber, alterations in density of the tip, as well as radiological evidence of a hollowed-out core. If an implanted UXO is suspected, risks to the surgical and anesthesia teams can be minimized by notifying the nearest military installation with EOD capabilities and following clinical practice guidelines set forth by the Joint Theater Trauma System.
\end{abstract}

http://thejns.org/doi/abs/10.3171/2015.6.JNS15779

KEY WORDS small arms ammunition; unexploded ordnance; UXO; implanted projectile; traumatic brain injury

I $\mathrm{N}$ military settings, it is not uncommon for patients to present with implanted craniofacial munitions that require surgical removal. In cases of implanted small arms ammunition, it can often be difficult to tell the difference between simple ballistics and ballistics associated with unexploded ordnances (UXOs). Given the rising prevalence of suicide bombings, this differentiation takes on additional significance. A proper understanding of small variations in clinical presentation and radiological features of munitions-associated injuries is useful in identifying projectiles with explosive potential.

Surgeons who remove implanted small arms ammunition associated with explosive ordnances are subjected to some degree of risk. Knowledge of the presence of these ordnances prior to surgery allows for additional prepara- tions that help to decrease the risk of intraoperative detonation. In the following report, we describe a case in which a patient presented with an implanted $12.7-\mathrm{mm}$ munition (approximately 0.50 caliber) that required evaluation for explosive potential by Explosive Ordnance Disposal (EOD) Company prior to surgical removal. Salient clinical and radiological features for risk stratification in this setting are discussed.

\section{Case Report}

History and Examination

A 23-year-old gravid female presented to the emergency department in considerable distress. On initial evaluation, she reported that a munition had ricocheted off a hardened

ABBREVIATIONS $\mathrm{ACH}=$ advanced combat helmet; $\mathrm{CJTH}=$ Craig Joint Theater Hospital; EOD = Explosive Ordnance Disposal; IOTV = improved outer tactical vest; UXO $=$ unexploded ordnance.

SUBMITTED April 5, 2015. ACCEPTED June 17, 2015.

INCLUDE WHEN CITING Published online February 2, 2016; DOI: 10.3171/2015.6.JNS15779. 
surface and struck her in the left cheek at her place of residence in a small nearby village in Afghanistan. Physical examination revealed stable vital signs. She had no vision in her left eye. Severe damage to the contents of her left orbit was noted. Aside from severe left ocular dysfunction, no other neurologic deficits were present. A small entrance wound present on her left cheek was suggestive of upward penetration into the maxillary sinus.

\section{Imaging}

Anteroposterior and lateral scout (preliminary) images were obtained (Fig. 1) and revealed an approximately 1.2 $\times 5-\mathrm{cm}$ metallic foreign body that appeared to have penetrated upward, through the maxillary sinus, terminating approximately at the floor of the anterior skull base. Computed tomography was performed, which confirmed penetration through the cribriform plate (Fig. 2).

\section{Surgical Preparation}

Prior to surgery, an obstetrics consultation confirmed viability and health of the fetus. Risks, benefits, and alternatives of the procedure were discussed with the patient and her family, and informed consent was obtained.

While the radiological appearance of the implanted projectile appeared to be most consistent with that of a 0.50 -caliber bullet, the presentation was unusual (implantation following ricochet). Additionally, the Taliban had recently advertised a new threat to the region in question, approximately 24 hours prior to the incident. These details raised suspicion for a potential UXO. The EOD team was notified and assisted with radiological stratification of risk prior to surgery. In concert with Craig Joint Theater Hospital (CJTH) Radiology, EOD team conducted imaging of 4 known projectiles -2 of which whose implantation would have posed an immediate risk to the surgical team (Fig. 3). These images were reviewed by a radiologist, the surgical team, and EOD personnel to gain an appreciation of features important in risk stratification.

Scout anteroposterior CT imaging of 4 available types
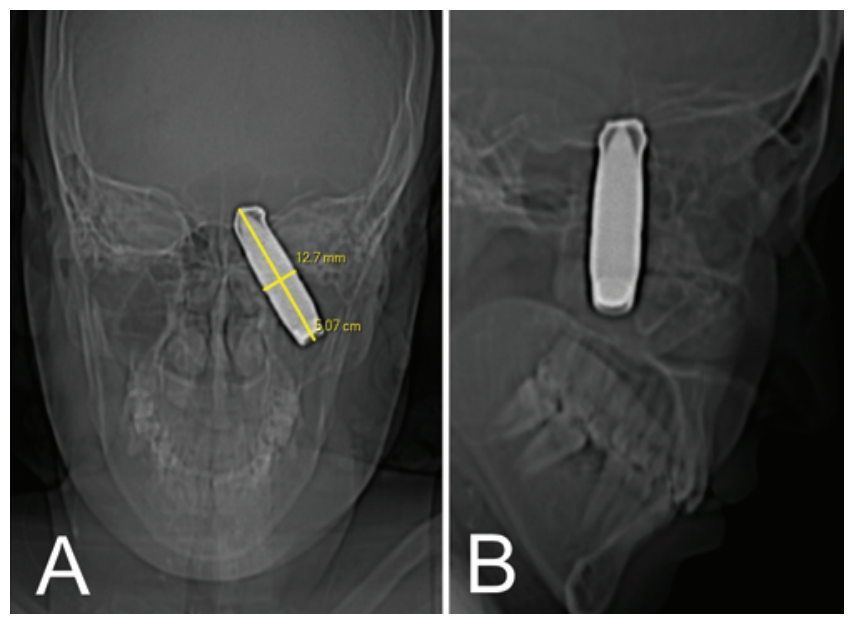

FIG. 1. Anteroposterior (A) and lateral (B) plain radiographs of the skull were obtained and revealed a $12.7 \mathrm{~mm} \times 5-\mathrm{cm}$ munition that had penetrated upward through the maxillary sinus and had become lodged in the floor of the anterior skull base. Figure is available in color online only.

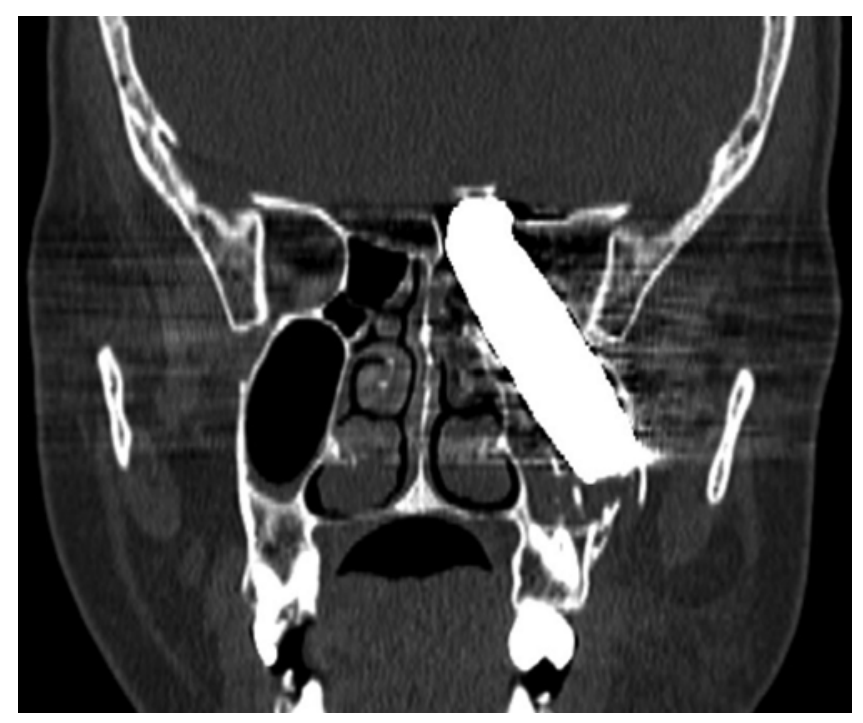

FIG. 2. Coronal reformats of CT images confirmed penetration through the cribriform plate.

of ammunition were obtained (Fig. 4). This imaging study was used to divide the munitions into 2 groups. The first group posed an immediate risk to the surgical team and included projectiles filled with tracer (Fig. 4A) and highexplosive (Fig. 4D) material. The second group posed no immediate risk (Fig. 4B and C).

The radiological evaluation by EOD Company did not reveal evidence of alteration in tip density or a hollowed-out core; thus, the risk of a UXO was believed to be low. Despite this low risk of explosive potential, plans were made for the operating room team to be minimally manned. Additional precautions published by the Joint Theater Trauma System were reviewed at this time. ${ }^{12}$ Following the aforementioned workup, a decision was made to perform the surgery within the main hospital rather than to set up an ancillary surgical site. In the operating room, all team members were fitted with improved outer

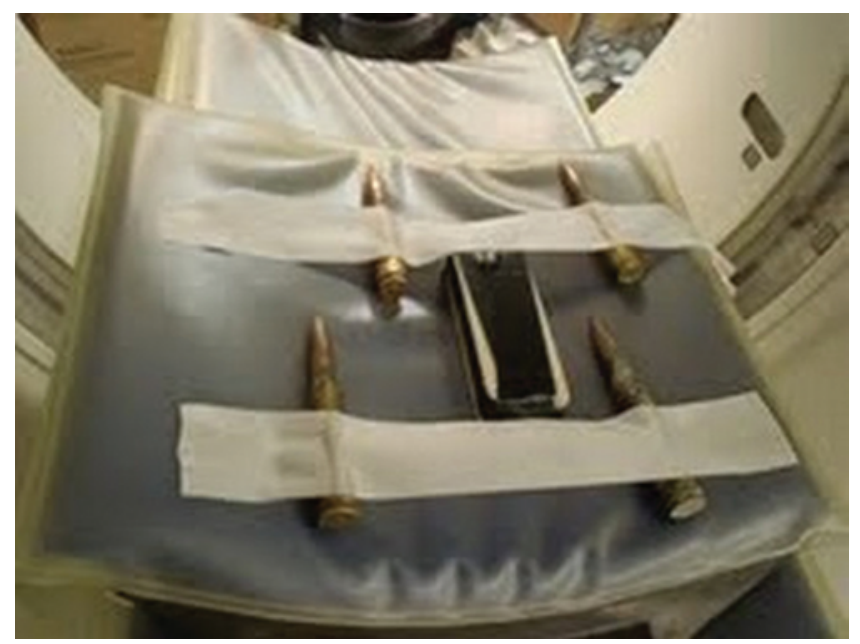

FIG. 3. Photograph of 4 projectiles prior to CT scanning (left to right): armor-piercing tracer, full metal jacket, armor-piercing high explosive, and armor piercing. A block of $\mathrm{C} 4$ is in the middle. Figure is available in color online only. 


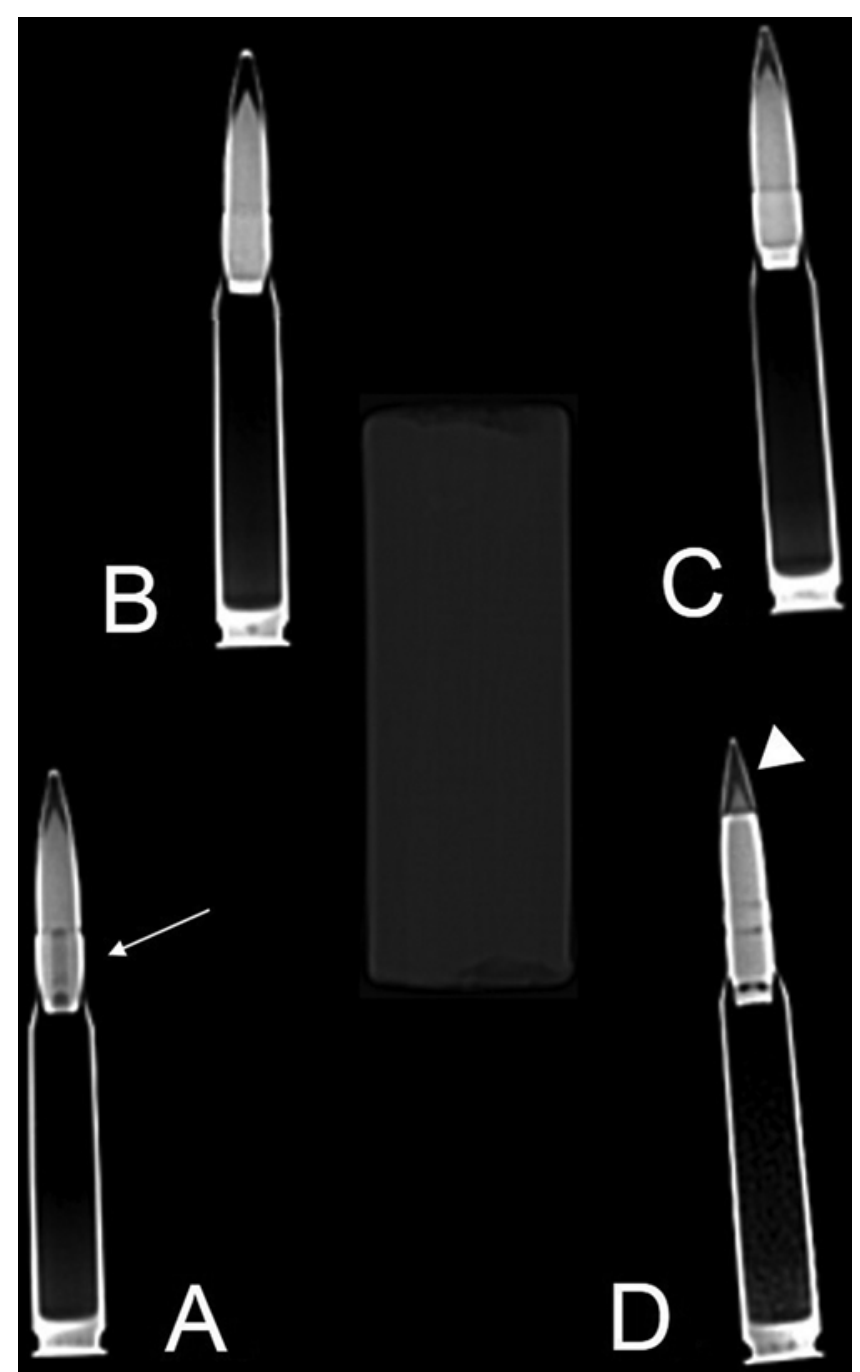

FIG. 4. Anteroposterior scout CT scans of 4 projectiles. A: Armorpiercing tracer projectile filled with tracer material; there is a cylindrical area of lucency in the base (arrow) that extends approximately one-third of the way toward the tip. This hollowed-out core is where the magnesium tracer resides. B: Full metal jacket projectile. C: Armor-piercing projectile. D: Armor-piercing high-explosive projectile filled with explosive material; there is a pattern of alteration of density in the tip (arrowhead) different from the other munitions that signifies the presence of explosive material. A block of $\mathrm{C} 4$ was placed in the middle to assess its appearance on $\mathrm{CT}$.

tactical vests (IOTVs) as well as advanced combat helmets (ACHs) with ballistic eye protection.

\section{Operation}

During induction of anesthesia, minimal manipulation of the face was performed. After preoxygenation, anesthesia proceeded with rapid sequence induction to avoid mask ventilation and minimize the risk of aspiration. Intubation was performed using direct laryngoscopy. A low $(20 \%-30 \%)$ fraction of inspired oxygen was used, given the potential flammable risk. While monopolar electrocautery was avoided during the procedure, the patient was electrically grounded to minimize accumulation of static electricity, which theoretically could trigger activation of



FIG. 5. A 12.7-mm ( 0.50 caliber) copper-jacketed, tungsten carbide core projectile with no associated explosive material was removed from the patient. Figure is available in color online only.

an ordnance. Because of the need for wide exposure of the munition prior to removal, a gingivobuccal incision was chosen over enlargement through the site of entry. A fullthickness mucoperiosteal incision was performed in the left maxillary vestibule to expose the comminuted anterior maxillary sinus wall. Following debridement of bone fragments, there was excellent visualization of the inferior half of the projectile. A $30^{\circ}$ Hopkins rod endoscope was used to better visualize all aspects of the projectile for purposes of classification by EOD Company. The projectile (Fig. 5) was gently dislodged from the skull base by the primary surgeon (T.N.) and rotated out of the maxillary sinus. Electrocautery was not used during access and removal of the object. Once the projectile was safely removed from the patient, tactical vests and combat helmets were removed and attention was turned to repair of the skull base defect.

After removal of the projectile, significant skull base and dural defects were noted, with associated CSF leakage. The surrounding ethmoid bone fragments were removed to provide clear visualization of the defect. Several options for repair of the CSF leak were discussed, including acellular dermis, fat, turbinate mucosa, and a nasoseptal flap. To decrease fetal exposure to anesthesia, the decision was made to proceed with repair using acellular dermis. A piece of Gelfoam slightly larger than the skull base defect was fashioned and placed in the epidural space. The acellular dermis was placed as an underlay graft and cessation of the CSF leak was confirmed. Another piece of acellular dermis was placed as an overlay graft and secured to the skull base with Surgicel (Ethicon) followed by Tisseel (Baxter Healthcare Corp.). Gelfoam was packed around the Tisseel and a Foley catheter was placed in the maxillary sinus to provide pressure on the graft.

\section{Postoperative Course}

The patient was successfully extubated at the end of the surgical procedure. Her postoperative course was complicated by some nausea and vomiting for the initial 48 hours. The Foley catheter was removed 72 hours after surgery. Throughout the remainder of her stay, the patient denied signs or symptoms of CSF leakage and no CSF rhinorrhea was identified on physical examination, including transnasal endoscopic examination prior to discharge. 
The patient was discharged home on postoperative Day 5. On routine follow-up 2 weeks after surgery, the patient reported unilateral facial pain but denied signs or symptoms of CSF leakage. A physical examination revealed a well-healed gingivobuccal incision with no evidence of CSF leakage. Absence of vision in the left eye remained unchanged.

\section{Discussion}

Credit for invention of explosive ammunition is given to Captain Norton of the British Army, who first employed its use in 1822. ${ }^{6}$ Explosive ammunition fell out of favor following the St. Petersburg Declaration of 1868 and the Hague Convention of 1899 , which in effect prohibited its use in times of war. ${ }^{11}$ However, the 1980s witnessed a resurgence in the use of exploding bullets. Perhaps the most famous incident involved the failed assassination attempt of President Ronald Reagan in 1981, in which the Devastator bullet that lodged in the lung of the president failed to explode following impact. The surgeons who removed this bullet were initially unaware that explosive ammunition had been used. ${ }^{6}$ However, the same group of surgeons would later remove another bullet that failed to detonate from the neck of a police officer, this time with knowledge of the explosive potential. Special precautions were taken during the latter surgery. Anecdotally, the bullet that struck White House press secretary James Brady during the shooting did, in fact, detonate inside his skull. The unstable nature of these munitions is illustrated by an event 10 days following the assassination attempt, in which an FBI agent unintentionally detonated one of the explosivetipped projectiles while handling it with tweezers. ${ }^{1}$

The majority of present-day explosive projectiles are available for purchase on the civilian market, but they are significantly more expensive than other ammunition and represent a minute portion of overall sales. This is, in part, due to regulation by the US Bureau of Alcohol, Tobacco, Firearms, and Explosives, and the National Firearms Act. ${ }^{4}$ Explosive-tipped projectiles are constructed similarly to hollow-point projectiles, with the exception that the hollow interior is filled with a pressure-sensitive explosive, such as lead azide. The force of impact detonates the explosive, which in turn expands "petals" constructed into the projectile. This "chemical" mechanism for expansion has a greater likelihood of failure than the "mechanical" mechanisms of hollow- and soft-tip projectiles. ${ }^{6}$

In cases in which implanted munitions are encountered, familiarity with patterns of traditional construction is useful. A bullet can be divided into 3 main components: the projectile, the case, and the primer. ${ }^{5}$ The projectile is the most likely part to be found implanted in the human body, as it represents the terminal component propelled out of the barrel of the firearm. Small arms ammunition, as defined by the US Military, consists of all calibers (sizes) of projectiles $30 \mathrm{~mm}$ (1.18 inches) and smaller. This designation encompasses more than 100 different calibers. ${ }^{2}$

Ammunition construction remains similar across various projectile sizes. Knowledge of variations in pattern of construction and/or radiological appearance can help determine whether an implanted projectile contains explo- sive material. The interior of the projectile is perhaps the most relevant to the topic of surgeon risk. It is here that explosive material is housed. The interior of the projectile is most often a lead/antimony mixture, but it can contain a variety of different components, including blended metal (powdered metal that is compressed), lead shot, plastic, tungsten or tungsten alloys, steel or steel alloys, and depleted uranium. ${ }^{5}$ These components can potentially be combined with or replaced entirely by a tracer element, an incendiary element, or an explosive element. It is these last 3 that present a risk of detonation during removal. In the presence of highly flammable substances in the operative environment, intraoperative detonation could have potentially catastrophic consequences for both patient and surgical team.

Clinical, radiological, and intraoperative evaluation all provide critical information that helps optimize patient care and minimize risk to the surgical team. This risk stratification process begins with initial evaluation of the victim. As with any patient who has suffered a penetrating injury, Advanced Trauma Life Support guidelines should be followed first, with assessment of airway, breathing, circulation, disability, and exposure. After any associated life-threatening injuries have been identified and managed, a more thorough examination should be conducted in conjunction with appropriate imaging. If only 1 wound is found on the patient or an odd number of wounds are noted, concern should be raised for a retained bullet, which, in a wartime setting, should be considered a UXO until proven otherwise (with appropriate precautions taken by the medical team). ${ }^{9}$ A history of the event should be ascertained from the patient or members of the transport team. Individual circumstances specific to the event will increase or decrease the likelihood that explosive munitions were used. Generally speaking, the likelihood of encountering implanted explosive munitions in a civilian setting is low, although anecdotal reports exist. ${ }^{7}$ Historically, assassination attempts have been linked to use of explosive munitions.

After a detailed clinical history and examination has raised suspicion of an implanted munition, the next step is radiological assessment. The initial imaging modality of choice is radiography, which provides important structural information. Both radiography and ultrasound imaging have been deemed safe in the setting of UXOs. ${ }^{8}$ Although the use of CT for imaging of implanted munitions has never been formally studied, anecdotal experience suggests that this modality also poses minimal risk. ${ }^{3}$ In the case presented above, CJTH radiology used plain films and CT scout preliminary imaging to evaluate the implanted munition. Reformatted CT imaging was useful in detailing neuroanatomical injury, but the large amount of metallic artifact made munition characterization difficult using this modality.

As reported above, radiographic imaging of the four 0.50 -caliber projectiles illustrated certain radiological characteristics that were suggestive of underlying explosive/flammable potential. These characteristics include a hollowed-out core in the base of the projectile (Fig. 4A) or unusual patterns of hypodensity involving the tip (Fig. 4D). Evaluation of munition size is also important in gaug- 
ing UXO risk. All munitions greater than $7.62 \mathrm{~mm}$ in caliber should be considered to have an explosive filler until proven otherwise. If, following initial clinical and radiological survey by the medical team, there is concern for retained explosive munitions, US Military EOD personnel should be notified to assist with identification and appropriate measures (e.g., operative precautions, cordoning of perimeter) prior to attempted surgical removal. CT imaging of the patient who presented with the implanted small arms ammunition in this case did not reveal any findings suggestive of an underlying explosive or flammable potential. Because of wartime conditions, EOD Company was notified. The munition was removed in the operating room without incident.

In the event that radiological characterization of the projectile is obscure, additional useful information can be obtained intraoperatively from gross visual inspection of the projectile. In particular, the presence of color bands is often associated with certain interior materials. The most common color associations of these bands are detailed below. ${ }^{2}$

Black tips signify antimaterial (armor piercing) projectiles. In the smaller calibers of ammunition, they are often a copper-jacketed tungsten steel alloy. Larger calibers may contain depleted uranium cores and are regularly marked with a black tip. These materials are extremely dense for their size and are adept at penetrating hardened targets. While there is no explosive risk, depleted uranium emits very low-level radiation and presents some biological hazard during removal and handling. The US Nuclear Regulatory Commission sets standards/conditions and issues licenses for the safe use, storage, and possession of these materials. Radiological variations with armor-piercing projectiles are subtle (the projectiles shown in Figs. 4A, $4 \mathrm{C}$, and $4 \mathrm{D}$ contain armor-piercing material).

Tracer projectiles, which are often marked with a red tip, allow a shooter to visually track a projectile as it travels downrange. The tracer projectiles are constructed with a hollow cavity in the rear of the projectile that is filled with a flammable material, such as magnesium (Fig. 4A). Energy from propellant detonation upon firing causes the magnesium to ignite while the projectile travels downrange. These projectiles pose a flammable risk to nearby objects, as illustrated by the historical utility of these weapons in combating hydrogen gas-filled German zeppelins during World War I.

Incendiary projectiles, usually marked by an orange tip, are those that contain an incendiary element in the nose, directly behind the sheathing. Incendiary projectiles work by the deformation of the sheathing and subsequent compression, with ignition of the incendiary element. The purpose of these projectiles is to light targets on fire, such as fuels. Originally, these projectiles contained phosphorus as the incendiary charge, which ignited on contact with oxygen. This component was changed to nitrocellulose during the buildup to World War II and has continued to change as technology advances. These projectiles were also used against zeppelins, but truly found their calling in use against aircraft, as the incendiary element is able to ignite fuel lines, fuel tanks, and lightly cased ammunition.

Explosive projectiles are typically marked with yellow, brown, or other double-banded colors. Marking with 2 bands that may consist of a variety of colors is sometimes used (red/white is the most common combination). These projectiles are designed to explode following impact. The act of explosion provides for more efficient transfer of kinetic energy to the end target and increases the presenting surface area and probability that vital structures are damaged. ${ }^{10}$ The general design of these projectiles is a copper sheath with an interior chamber containing a pressure-sensitive explosive material (Fig. 4D). Upon impact, the copper sheath deforms, compressing the explosive inside until it detonates. The sensitive material may be explosive in nature or of incendiary composition. In the latter scenario, compression of the incendiary material is used to detonate adjacent explosive material. Occasionally, fuses are used, which are mechanisms that contain small amounts of highly sensitive explosives to set off larger amounts of less sensitive explosives. In general, the greater the amount of compressive force, the greater the risk of detonation/ignition and the greater the danger.

Much of the information above is specific to workup following radiological identification of an implanted 12.7$\mathrm{mm}$ munition. However, the topic of prevention of accidental UXO discharge can be extended to other forms of munitions (implanted mortars, rocket-propelled grenades, 40-mm projectiles, etc.). In the event that a patient presents with an implanted UXO, there are basic rules to follow. Light, electricity, heat, and pressure are known to potentiate discharge of UXOs; every attempt should be made to minimize these factors both prior to and during operative removal. ${ }^{12}$ EOD staff should be notified as soon as a UXO is suspected and will provide a professional opinion on probability of detonation. If helicopter travel to the hospital is contemplated, the patient should be grounded to prevent accumulation of static electricity. During transit and workup, the position of the patient should be kept close to the position in which he or she was found, as unintentional pressure on the UXO can result in detonation. The area in which the patient is located should remain cordoned off and all nonessential personnel should be evacuated from this area. Essential personnel should be fitted with IOTVs as well as ACHs with ballistic eye protection. If there is high suspicion for a true UXO, surgical removal should be performed in an ancillary surgical site away from the main surgical facility. Electrocautery should be avoided during surgical removal. The unit commander and primary surgeon should attempt to limit the number of essential personnel to the absolute minimum. Surgeons should "gown and glove" over battle-protective equipment. Following induction of anesthesia, the anesthesiologist should move away from the ancillary operating room during UXO removal. Every attempt should be made to limit supplemental oxygen, which might serve to magnify combustion in the event of detonation. If at all possible, the ordnance should be removed in a delicate manner before treating other injuries.

\section{Conclusions}

The presence of specific clinical settings (e.g., wartime, assassination attempt) and radiological features (e.g., size 
greater than 7.62-mm caliber, alterations in density of the tip, hollowed-out core) should prompt suspicion for an implanted UXO. If a UXO is suspected, appropriate preparations should be made to minimize risk to the surgical and anesthesia team.

\section{References}

1. Altman LK: The doctor's world. New York Times. May 25, 1982. (http://www.nytimes.com/1982/05/25/science/thedoctor-s-world.html) [Accessed September 9, 2015]

2. Fedoroff B, Sheffield O: Encyclopedia of Explosives and Related Items. Springfield, VA: US Army Armament Research and Development Command, Weapons Systems Laboratory, 1975, Vol. 7

3. Hagan C: Military docs pluck live shell from soldier's head. CNN. April 15, 2010. (http://www.cnn.com/2010/ HEALTH/04/15/unexploded.shell.head.afghanistan/) [Accessed September 9, 2015]

4. Internal Revenue Code, 26 USC $\$ 5845$ (http://www.gpo.gov/ fdsys/pkg/USCODE-2010-title26/pdf/USCODE-2010-title26subtitleE-chap53-subchapB-partI-sec5845.pdf) [Accessed September 9, 2015]

5. Jandial R, Reichwage B, Levy M, Duenas V, Sturdivan L: Ballistics for the neurosurgeon. Neurosurgery 62:472-480, 2008

6. Knight B: Explosive bullets: a new hazard for doctors. $\mathbf{B r}$ Med J (Clin Res Ed) 284:768-769, 1982

7. Knight M: Explosive Ordnance Disposal sergeant removes live grenade from man's leg. WTKR News. October 16, 2014. (http://wtkr.com/2014/10/16/explosive-ordnancedisposal-sergeant-removes-live-grenade-from-mans-leg/) [Accessed September 9, 2015]

8. Schlager D, Johnson T, McFall R: Safety of imaging exploding bullets with ultrasound. Ann Emerg Med 28:183187,1996
9. Spitz WU: Injury by gunfire: Part I. Gunshot wounds, in Spitz WU, Fisher RS (eds): Medicolegal Investigation of Death. Springfield, IL: Charles C Thomas, 1993, pp 311-381

10. Swan KG, Swan RC: Wound ballistics for the civilian surgeon. Surg Annu 17:163-187, 1985

11. Swift B, Rutty GN: The exploding bullet. J Clin Pathol $\mathbf{5 7 : 1 0 8 , 2 0 0 4}$

12. Unexploded Ordnance Management: Joint Theater Trauma System Clinical Practice Guidelines. United States Army Institute of Surgical Research. (http://usaisr.amedd.army.mil/ cpgs/Unexploded_Ordnance_Management_7_Mar_12.pdf) [Accessed September 9, 2015]

\section{Disclosures}

The authors report no conflict of interest concerning the materials or methods used in this study or the findings specified in this paper.

\section{Author Contributions}

Conception and design: Forbes. Acquisition of data: Forbes, Ryhn, T Newberry. Analysis and interpretation of data: Laughlin, S Newberry, Pasley, T Newberry. Drafting the article: Forbes, Pasley, T Newberry. Critically revising the article: Forbes. Reviewed submitted version of manuscript: Forbes. Approved the final version of the manuscript on behalf of all authors: Forbes. Administrative/technical/material support: Laughlin, T Newberry.

\section{Correspondence}

Jonathan A. Forbes, Department of Neurological Surgery, David Grant Medical Center, Travis AFB, 32 Parkside Dr., Davis, CA 95616. email: jonathan.a.forbes@gmail.com. 